\title{
Do student teachers see what learners see? - Avoiding instructional dissonance when designing worksheets
}

\begin{tabular}{|c|c|}
\hline \multicolumn{2}{|c|}{$\begin{array}{l}\text { Authors: } \\
\text { Rinelle Evans }{ }^{1} \text { (D) } \\
\text { Ailie Cleghorn }{ }^{2}\end{array}$} \\
\hline \multicolumn{2}{|c|}{$\begin{array}{l}\text { Affiliations: } \\
{ }^{1} \text { Department of Humanities } \\
\text { Education, Faculty of } \\
\text { Education, University of } \\
\text { Pretoria, Pretoria, } \\
\text { South Africa }\end{array}$} \\
\hline \multicolumn{2}{|c|}{$\begin{array}{l}\text { ²Department of Education, } \\
\text { Faculty of Arts and Science, } \\
\text { Concordia University, } \\
\text { Montréal, Quebec, Canada }\end{array}$} \\
\hline \multicolumn{2}{|c|}{$\begin{array}{l}\text { Corresponding author: } \\
\text { Rinelle Evans, } \\
\text { rinelle.evans@up.ac.za }\end{array}$} \\
\hline \multicolumn{2}{|c|}{$\begin{array}{l}\text { Dates: } \\
\text { Received: } 10 \text { April } 2021 \\
\text { Accepted: } 17 \text { Nov. } 2021 \\
\text { Published: } 18 \text { Feb. } 2022\end{array}$} \\
\hline \multicolumn{2}{|c|}{$\begin{array}{l}\text { How to cite this article: } \\
\text { Evans, R. \& Cleghorn, A., } \\
2022, \text { 'Do student teachers } \\
\text { see what learners see? - } \\
\text { Avoiding instructional } \\
\text { dissonance when designing } \\
\text { worksheets', South African } \\
\text { Journal of Childhood } \\
\text { Education 12(1), a1015. } \\
\text { https://doi.org/10.4102/ } \\
\text { sajce.v12i1.1015 }\end{array}$} \\
\hline \multicolumn{2}{|c|}{$\begin{array}{l}\text { Copyright: } \\
\text { (C) 2022. The Authors. } \\
\text { Licensee: AOSIS. This work } \\
\text { is licensed under the } \\
\text { Creative Commons } \\
\text { Attribution License. }\end{array}$} \\
\hline \multicolumn{2}{|l|}{ Read online: } \\
\hline 回的回 & $\begin{array}{l}\text { Scan this QR } \\
\text { code with your } \\
\text { smart phone or } \\
\text { mobile device } \\
\text { to read online. }\end{array}$ \\
\hline
\end{tabular}

Background: The judicious use of worksheets ought to contribute to the establishment of literacy, with a special significance for multilingual classrooms where neither teachers nor learners are mother tongue speakers of the instructional language. Disparity between the pedagogical intention of the worksheet and learners' interpretation of the message often creates instructional dissonance.

Aim and setting: The aim of this nested study was to establish the quality, and (mis)use of worksheets as implemented by student teachers during their work-integrated learning stint in selected urban South African primary schools.

Design and methodology: Using a self-designed grid, a qualitative document analysis underpinned by visual ethnography was conducted on 45 worksheets. These texts were prepared by the student teachers for literacy, numeracy and life skills lessons offered to 6- to 9-year-olds. Criteria used for the simple analysis included appropriateness for the age group, visual complexity, accuracy of language use, cultural compatibility, layout, clarity of instructions and alignment with expected learning outcomes.

Findings: Findings suggested the hasty conceptualisation and creation, or inappropriate choice of worksheets used as learning support material. Apart from linguistic barriers because of poorly formulated tasks, the worksheets were generally culturally insensitive, and contained grammatical inaccuracies compounded by technical and design shortcomings. These lacunae defeated the pedagogical purpose of most worksheets and generated instructional dissonance.

Conclusion and implications for teacher education: The careful crafting and implementation of worksheets coupled with sound content knowledge of language and literacy principles would alleviate learner bafflement and enhance the learning opportunity. We take the position that well-designed worksheets should serve a focused purpose and link directly to literacy and learning of the instructional language.

Keywords: cultural sensitivity; foundation phase; instructional dissonance; learning support materials; worksheets.

\section{Introduction}

A common feature of well-resourced early childhood classrooms is the abundance of print-rich materials used in a variety of ways for fostering learners' introduction to literacy and numeracy. Walls, cupboards, doors - in fact - any open surface - are generally covered in alphabet letters, picture charts, number cards and life skills-related pictorial material that teachers supposedly implement as learning support material.

Whilst mentoring fourth year student teachers during their work-integrated learning placements and in particular, during our observational visits to their foundation phase classrooms, we were struck by how frequently another form of visual material, namely worksheets, was used. This single page - always handed out at the end of a lesson - would have simple exercises or questions that the learners needed to complete individually as further practice or consolidation of what had been taught that day. A completed worksheet, regardless of the accuracy with which it was done, purportedly provided tangible evidence of the work done in the class or assigned as homework.

Our post-observational discussions suggested that the importance of implementing a carefully crafted worksheet is generally not fully recognised in teacher education programmes and these student teachers had not been guided to design worksheets which could support literacy acquisition. They were inclined to draft or print off a 'worksheet' indiscriminately which seemed to entertain or keep learners busy rather than enhancing learning. We noted too that the judicious 
use of worksheets as a learning support or means of assessment was, at times, also compromised by inappropriate commercial or foreign products offered by minority world companies with monetary interest (Alonso-Sanz \& Rueda 2021) or generic ones commissioned by education departments in an attempt to standardise the curriculum. We thus asked what pedagogical intention could be deduced from the content and implementation of worksheets designed by foundation phase student teachers.

This article discusses the design and (mis)application of teacher-made worksheets, used by South African student teachers during their 24-weeks internship at four urban schools in a large metropolis where the language of instruction is English from Grade 1 and in light of the findings, offers practical guidance for designing or selecting worksheets.

\section{Literature review}

Our literature searches suggested research paucity related to the design and implementation of worksheets specifically in the field of early literacy. Not even the current prescribed South African curriculum had anything to suggest with regard to the design and implementation of worksheets in the foundation phase. The studies we found used a quantitative methodology and pertained to Science, Technology, Engineering, and Mathematics (STEM) subjects and secondary or university schooling (Amila et al. 2018; Çelikler 2010; Choo et al. 2011; Lee 2014; Töman et al. 2013). These studies mainly measured the effects of worksheet use on conceptual understanding, academic achievement or improvement. An Indonesian study conducted by Simbolon et al. (2018) attempted to design and validate worksheets using a scientific approach to product development. Choo et al. (2011) found that Singaporean undergraduates had reduced feelings of choice and autonomy when using worksheets as scaffolding for problem-based learning nor did they play a significant role in enhancing learning as initially assumed. A notable exception was a qualitative study conducted with pre-service elementary teachers by Sasmaz-Ören and Ormanci (2012) in which they gauged how well these students could develop worksheets for science and technology lessons and also determined their opinions of the project. The literature review presented by these two researchers appears comprehensive in terms of worksheets as assistive material but as the original sources had been written in Turkish, was unfortunately not accessible to us.

We thus believe that our exploratory study may open avenues for discussion on how worksheets - their design, implementation and probable effect on instruction could contribute to the development of literacy, numeracy and life skills in the South African foundation phase classroom. Underpinned by the work of Peacock, Cleghorn and MikkilaErdmann (2004), we framed our study within the teacherlearner-text (TLT) triad - a model based on meaningful engagement within a classroom arising from interaction between physical and social forces where in this study, we consider the worksheet as text.

In a teacher-centred classroom, the direction of interactional flow is primarily from the teacher to the learners, with the teacher mediating, verbally and with gestures; learners' interactions with the text could include chalkboard writings, posters, flashcards and, in our case, worksheets. There are observable patterns in which learners are guided towards the language and content of text materials, as well as the ways in which learners relate to the text on their own. The patterns of interaction can vary noticeably, depending on, for example, the number of learners in the classroom and how they are configured in groups or seated as a single large group. These patterns shift markedly when on-screen materials are used, a situation that did not occur in any of our classroom observations because of the limited availability of computers or tablets. Despite this, the ease with which on-line material can be accessed and the range available imply that teachers need to appraise existing material critically before implementing any in their classrooms.

Drawing on an explanation provided by Choo et al. (2011), we define a worksheet as an instructional tool consisting of a set of tasks aligned with the learning objective and designed to guide learners systematically in their understanding of concepts or mastery of skills. A commonly accepted advantage of using worksheets is the anticipation that all learners in a class would simultaneously and actively be participating in a learning opportunity (Çelikler 2010). In some contexts, these materials are called activity sheets (Fauziah \& Nurita 2019; Simbolon et al. 2018) - an appellation we did not favour as we consider an activity to be a general description of behaviour teachers expect learners to execute, for example, move to the front, open their books or mark homework. By implication, many lessons are often characterised by plenty of activity but few of these routines or instructions, in fact, lead to meaningful learning. We would like to think of a worksheet as a task sheet, that is, the learner is required to perform some meaningful action or cognitive process in order to reach a better understanding or mastery of content. Completing a worksheet is thus a focused behaviour in which learners engage with the new content in order to deepen their understanding, for example, looking up words in a dictionary, or listening to distinguish fact from opinion (Van der Walt \& Evans 2019).

In addition, we acknowledge that learning support materials, whether print and non-print, have manifest and latent functions (Alonso-Sanz \& Rueda 2021; McEneaney 2004; Peacock \& Cleghorn 2004; Prochner, Cleghorn \& Green 2008). A definite function is to give learners access to the subject knowledge that curriculum experts and policymakers have decided is essential. On the other hand, the latent functions generally relate to the hidden curriculum, often socialising children into 'unequal social hierarchies, usually mirroring discriminatory practices and structures in the classroom and school' (McEneaney 2004:22). Gay (2001) reminded us about 
the symbolic curriculum where spaces in the school often publically display images, statements of etiquette, rules or learner achievements, subtlety valorising what and who is important. The role that the written word and pictorial matter plays in the socialisation of learners into the customs and culture in which they live can thus not be underestimated. Worksheets, whether locally constructed or commercially developed, ought not to be culturally unfamiliar to learners. Apart from determining whether a worksheet is aligned with the pedagogical purpose of a particular lesson, its cultural fit with the teaching context and learners also needs to be matched because so much of what is available represents a western and globalised world (Cleghorn \& Prochner 2010; Hoyos Vivas 2021; Prochner et al. 2014; Kirova et al. 2016b) often unfamiliar to young South African learners.

A case in point we witnessed were two posters, one depicting cherub-like naked, Caucasian toddlers used to illustrate motivational quotes with the other showing a wizard, toadstools, castles and a typically British king dressed with ermine and seated on an elaborate throne. These were pasted up in the corridors of a primary school serving an exclusively but diverse African population. This goes against the grain of culturally responsive teaching which requires that all learners feel comfortable with teacher behaviour and classroom practices.

There thus often exists incongruity between the pedagogical message of the text, the 'worldview' of the learners and locally accepted or favoured teaching approaches (Peacock \& Cleghorn 2004:181) resulting in what Evans and Cleghorn (2012) refer to as 'instructional dissonance' (p. 89).

Instructional dissonance refers to any communication between the teacher and learners that has been affected by distortions of meaning. Stated differently, instructional dissonance refers to communicative instances that do not 'make sense', when learners clearly do not understand or are confused by what they are supposed to do. Although generally related to the teacher's instructions or explanations that are not understood, the potential complexity of interaction within the TLT became obvious as we questioned the choice/design, and implementation of the worksheets.

Furthermore, an implicit if not explicit goal in Grades $\mathrm{R}$ to 3 is the development of the instructional language in order to progress scholastically. Inevitably, working with print materials during instruction entails the use of language and the teacher thus has the added responsibility of judiciously selecting or designing appropriate visual materials in order to contribute to the development of language and literacies. Currently, in South Africa, national policy advocates for mother tongue instruction in the first 3 years of formal schooling with a switch to English in Grade 4. However, in urban metropoles, the diversity amongst learners in terms of language and culture is so broad that the common denominator in the classroom becomes English as the instructional language. Print materials thus take on special significance in multilingual classrooms where often neither the teacher nor the learners are mother tongue speakers of the language used for instruction. The TLT interaction thus takes on distinct significance in linguistically diverse classrooms because much of the commercial and imported text materials, if present at all, are produced as if learners are mother tongue speakers of the language in which that text is written.

Cleghorn and Prochner's study (2010) on the influence of globalisation in early childhood settings in Canada, India and South Africa raises awareness that there is much work to be done in early childhood programmes to diverge from the Euro-American view that predominates, to an integrated approach that embraces indigenous perspectives in early childhood teacher education. African voices calling for the same include Marfo and Pence (2008), Mwaura and Marfo (2011), Matengu and Cleghorn (2020), Matengu (2021).

\section{Research methods and design}

Visual ethnography as a qualitative research method focuses on the collection and analysis of visual data, for example, artefacts that one can actually see like photographs taken in and out of classrooms over an extended period of time (Pink 2013). Images are central to the analysis whilst the relationship between the visual and cultural practices is of significance (van den Scott 2018). Visual ethnography also offers a reflexive stance to theoretical, methodological, practical and ethical issues in field research.

For the main longitudinal study first reported in Evans and Cleghorn (2012), we had designed an open classroom observation schedule with the initial intention of exclusively observing the patterns of interaction and language use between the student teachers and foundation phase learners. We soon noted during our observations that no reference was made to the materials posted on the classroom walls explicitly attending to language development. Such attention would have had the potential to encourage language awareness and early literacy development. We asked why an item was located where it was, who had put it there and with what purpose in mind? We soon realised that printed media provided a striking form of instructional dissonance when we saw the word 'pink' printed on a green flashcard, whilst in another class, the flashcard 'This is the ceiling. It is very high' was pasted at adult eye-level against the wall at the entrance. We extended our gaze from these cultural and linguistic incongruities within the visual or verbal content of the print material pasted up on walls and books located in reading corners to include worksheets as an incidental side interest because our wide-in-scope procedure provided multiple opportunities for gathering such print materials. The broad question posed in this study during the course of on-going qualitative research carried out in several urban pre- and primary schools for which ethical clearance had already been granted by the institutional review board. (Cleghorn \& Prochner 2010; Evans \& Cleghorn 2012). 
Our fresh line of enquiry thus became the pictorial and textual analysis of worksheets, created by student teachers. We gathered data in the form of 45 worksheets provided to us by student teachers who had been assigned to various foundation phase (Grade 1 to 3 ) classes found across the range of inner-city government schools to privately funded learning centres in a large metropolis of South Africa. Although numeracy and life skills lessons were of interest, we focused primarily on worksheets that covered topics related to literacy taught to learners (aged 6-9) by the student teachers.

We developed an analytical grid using criteria drawn from sources that offered suggestions for designing effective worksheets (Friends of the Earth 2008; Frost n.d; Graham 1998; Hall \& Russac 2012; Kennedy 2016; Röken 2015; Worksheet Library 2007; University of Texas, 2010). We analysed the worksheets in terms of alignment with predetermined learning outcomes, appropriateness for the target audience which included complexity and accuracy of language use, cultural compatibility, cognitive demand for the age group and purpose. Other criteria related to clarity of written instructions, layout and visual appeal. We independently evaluated each worksheet and manually populated the grid. Inter-rater reliability between the two researchers was high. The majority of the lessons in which the worksheets were used had been observed by at least one of the authors and suggested that student teachers unquestioningly modelled the implementation of the worksheets during a lesson on their mentor teacher's practice. With hindsight, we ought to have been more meticulous about documenting the actual implementation.

\section{Presentation and discussion of findings}

We offer a concise summary of the key findings related primarily to the analysis of worksheets augmented by our formalised classroom observations of student teachers in situ.

\section{Creation of worksheets}

An overview of all worksheets suggested the uncritical thinking with which student teachers seemingly rushed to prepare a master copy and duplicate it prior to starting their lessons. Even worksheets used in the past exhibited no sign of having been revised for the new group. To illustrate, the week in which the topic 'Reptiles' was taught, learners were required to complete a worksheet in which a dozen words representing final blends (-st $+-m p)$ needed to be paired with 12 pictures. Although the layout was logical and the images clear, they were difficult to interpret as some suggested nouns and others verbs with no visual indication of action or movement. The image of a tent (final blend -nt) was particularly confusing as it had been used to suggest the verb camp. Furthermore, Grade 2 learners found it difficult to distinguish between hump [of a camel] and lump [on a child's head] as low frequency words. An image of a bicycle pump was illustrated in an unusual manner making it an unfamiliar object to city learners who largely travelled by car or public transport. Apart from the pictures being problematic to interpret, not a single one represented a reptile. Our expectation was that there would have been constructive alignment between the lesson topic and its content, especially because recycling and task-chaining of language items are common principles in language learning.

What we witnessed during our observations was borne out by our analysis: student teachers did not spend time conceptualising a worksheet to ensure that its pedagogical purpose was closely linked to the learning outcome but prepared it as a concluding activity to their lesson. Nor did they reflect upon the consequence that an inappropriate layout or confusing content could have on learners especially those who were still acquiring the language of instruction. Although not part of the data collection process, our postobservation discussion revealed that students were still developing their pedagogical content knowledge and had thus made inappropriate value judgements about what the worksheets were supposed to achieve.

Although we did not witness in person all the lessons from whence we collected worksheets, it was clear from the mesoscheduling and our knowledge of the foundation phase curriculum that there was a negligible alignment between lesson plans and the instructions printed on the particular worksheet handed out. It was frequently not clear what learners were to gain by completing the worksheet.

With our distinction made earlier between task and activity, very few worksheets required learners to engage meaningfully with a task. Although it could be argued that some worksheets might be considered practice sheets, for example, arranging letters alphabetically, colouring in segments of shapes, most called for learners to merely 'do' something, for example, formulating decontextualised sentences unrelated to the topic rather than consolidate the new content taught by making a clear link.

\section{Obscure learning outcomes}

The appropriate formulation of learning outcomes requires a separate in-depth study as student teachers have apparently not mastered this key pedagogical principle adequately even as late as the third quarter of an academic year. In many instances, we wondered what the student teacher had set out to achieve by having the learners complete the worksheet as the learning outcome was obscured not only by poor visual material but also by incoherent/non-existent instructions or incorrect grammar. Figure 1 illustrates a clear mismatch between lower-level skills required for forming letter shapes and the typical intention of completing a maze task although both require fine motoric skills.

The lesson had been about recognising and forming the lower-case letter ' $\mathrm{p}$ '. The worksheet was created to reinforce the shape of the letter taught. Learners were 


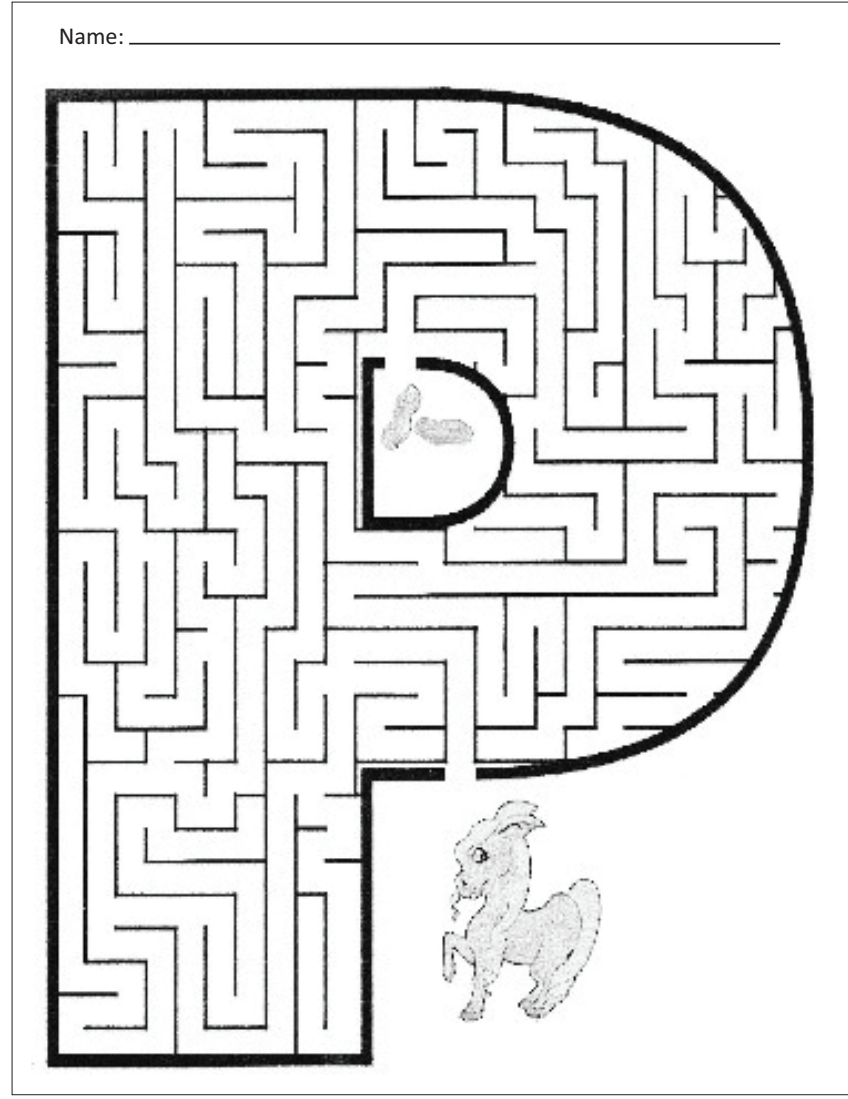

Source: School A Grade 12017

FIGURE 1: Worksheet prepared for Grade 1 learners to practise forming the letter ' $p$ '.

instructed to lead the pony through the maze (a foreign concept not explained and the movement pattern having no direct link to the formation of a ' $\mathrm{P}$ ') to find the peanut in the centre (not easily recognisable as such and easily confused with the known: animal droppings!). Furthermore, the letter P, as illustrated, was uppercase and did not have the required long 'tail' of the lower-case letter that the teacher had emphasised earlier, whilst the centre of the maze resembled the upper-case letter ' $D$ ' somehow echoing the truncated letter ' $\mathrm{P}$ '. This visual blunder defeated the entire purpose of the worksheet apart from perhaps allowing the learners to practise their fine motoric skills.

Apart from these stylistic features, comprehension was confounded by cultural boundaries. Although it would be obvious to an adult that the two images (pony and peanut) had been chosen to represent the letter being taught, this was not emphasised nor were the new words practised audibly. It may have served to reinforce the shape of the letter if the words 'pony' and 'peanut' had appeared on the worksheet. Additionally, some learners labelled this animal a donkey which is a more common sight in South Africa. The word and image of 'pony' would probably only be recognised by upper-middle class learners familiar with equestrian experiences or those who watch Disney movies. The worksheet did not reinforce the apparent manual skill of mastering a lower (or was it supposed to be

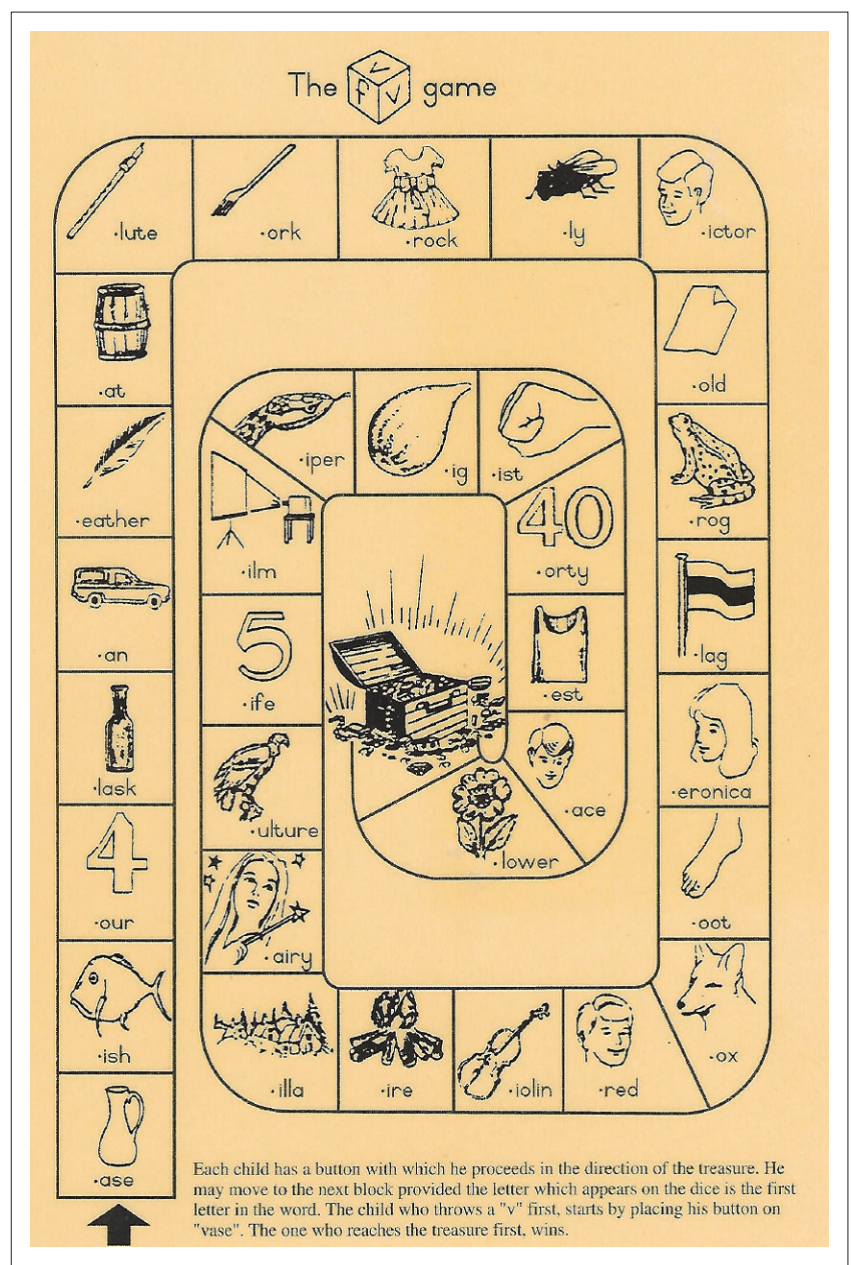

Source: School QA Grade 32018

FIGURE 2: Worksheet prepared for Grade 3 to practise voiceless $f$ and voiced $v$ sounds.

an upper case?) letter ' $\mathrm{p}$ ' as the pictorial matter could not be decoded easily. It was also one-dimensional, indistinct and culturally unfamiliar.

\section{Culturally insensitive choices}

As already alluded to above in Figure 1, it was glaring how many worksheets were culture bound and exclusionary, not only in terms of the physical portrayal of blonde, fairskinned faces and limbs, but also in terms of Eurocentric household items and activities associated with a privileged life-style. For example, in Figure 2, a worksheet used in Grade 3 to distinguish the voiced ' $\mathrm{v}$ ' and voiceless ' $\mathrm{f}$ ' sounds, even the treasure chest a player needs to reach in order to win would be unfamiliar unless learners had encountered such an image in a (Western) fairy tale or pirate movie. In order to be interpreted correctly, the lines suggesting the glitter and sparkle of gold or jewels require a sophisticated visual literacy. The image is further compounded by the lack of distinguishing colour. To a young local learner, the lines may well signify tall grass in which a wooden box has been hidden/found filled with 'stuff'. One also wonders what inner-city learners or their caregivers would make of villas, violins and vats - key elements of the game! 
Of the 34 images, represented in Figure 2 at least half would not be easily recognisable because of decontextualisation, skewed proportion, inaccurate representation or shape. One attempted to depict a verb without any directional arrow suggesting the action 'fold' whilst most images suggested a noun. Also problematic were the British and, in many cases, archaic names of Victor, Veronica and Fred, whilst another blonde boy's head was used to suggest a face - again without any directional arrow for guidance. Yet another blonde depiction of a long-haired girl with a wand and several stars set above or behind her suggested 'fairy' - an unusual image as often fairies are drawn with wings to at least suggest their non-human qualities.

Even for mother tongue speakers of English, too many items would not be known by the label required, for example, vase (jug), flask (bottle), van (hearse/truck), frock (dress), fox (dog), violin (guitar), vulture (hadida - a large indigenous bird), viper (snake), fig (gourd) and vest (T shirt). Others graphically depicted an unknown object, for example, vat, flute, violin, villa or film. Three images (fork, flute, fire) are not easily distinguishable as they have not been drawn to scale or clearly enough. And finally, the numeral five may well be recognised but confusion is sown when the remaining letters of the word have been misspelt! (fife). We also felt that apart from being rendered in exclusionary (sexist) language (he, his), the written instructions ought to have been adapted for easy comprehension by learners.

Based on our knowledge of the learners' home communities (Evans \& Cleghorn 2012), few would have caregivers or siblings who could offer direction let alone help decode culturally foreign/out-dated concepts or depictions as found on the worksheets, often expected to be completed as homework.

\section{Clarity and accuracy of language}

Some worksheets were too difficult in terms of the language used for the age group whilst learners were often expected to read and write at levels beyond their current knowledge of English. Although Grade 1 learners would not be required to read instructions upon starting school, the reading demand placed on learners in high grades was a challenge in many instances because of syntax and sentence length.

We found ample evidence of teachers' difficulty with English expression, punctuation and even spelling. Mistakes in the worksheets, we ascribed to teacher haste. In rare instances, the learners noticed a mistake on a worksheet and pointed it out upon which the teacher rectified it immediately. Moreover, apart from the mistakes, the language used for instructions (at times given orally) was often too advanced and complex for young second language learners. Although English usage mistakes may be considered minor and ascribed to the influence of the teacher's mother tongue (e.g. 'Welcome in the classroom' rather than 'to'), misspelt words or careless letter formation added to the young learners' confusion as they struggled to perform the tasks that were expected of them. For example, grammatical errors occurred frequently in decontextualised words and sentences, punctuation marks were missing, words were misspelt, technical terms misused. These, no doubt, added to the complex language encounters experienced by many young English language learners, for example:

Make these words mean the opposite (antonyms) by choosing from the prefixes below:/Write 10 sentences with the vocabulary words:/Fit the pictures to the sentences that describe them:/ What fractions are green?/Circle the word that will finish each sentence./Highlight each long word in the box then write the name of each picture on the line./What do most insects have and how many do they have? (Evans \& Cleghorn 2012:95)

Furthermore, individual exercises or tasks were not graded from simple to more challenging. A careful sequencing would have created a more meaningful learning task. There were also marked discrepancies across the worksheets between the levels required by each grade with a substantial raising of the bar in Grade 3. Many practice sentences were used as discrete items and had no binding context. Referring back to the lesson in which reptiles (called animals on the worksheet - a factual inaccuracy) were the topic of discussion, the set of worksheets were replete with disconnected sentences which were not linked to the topic at all. A good opportunity for Grade 3 learners to use language beyond sentence level was lost.

\section{Design elements}

In terms of the design elements, there was room for improvement in most cases: a noticeable technical gap was worksheets not having a space for the learner's name or date. Often, there was no indication of the topic or by whom the worksheet had been prepared. The origin of the source information was also missing. The addition of such information would facilitate class organisation and systematic reporting as well as future referencing. Some worksheets lacked headings or had incongruous numbering. The layout of text although limited by page size could be enhanced by using textboxes, and indentations or frames. In all instances, the choice of font type and size was acceptable as the prescribed foundation phase font had been applied. The visual quality of the worksheets was adequate in terms of clarity but not all pictorial matter was easily identifiable some images were too small, some too detailed. The distracting, and at times, confusing use of capitals, bold and underlining suggested emphasis where it was not necessarily needed. One worksheet had the numerals 4, 3, 2, 1 printed at the bottom and our assumption was that this was used to establish how learners felt about completing the worksheet. However, the reverse order of the numerals may have been confusing to those who were learning to count and were accustomed to seeing them in the order of 1 , $2,3,4$. In a probable attempt at making the worksheet appear interesting, the teacher had added 'eye junk' or visual clutter in the form of patterned borders, unnecessary wording in loud WordArt and meaningless, unrelated ClipArt pictures. 
To sum up, our analysis revealed that many worksheets were cluttered with non-teaching points making the layout so 'busy' that assistance was required from the teacher or from a more knowledgeable peer to decode and negotiate the page successfully. Studying the student teachers' written lesson plans confirmed that few worksheets were designed for specific learning purposes with the sole aim of expounding a lesson's content or as Graham (1998:1) says, 'designed to create a sense of mystery and discovery, inviting learners to notice and explore'.

\section{Implementation of worksheets}

All worksheets were designed to be completed individually and no assessment key or rubric was provided. Observations showed that teachers merely walked from desk to desk checking on learners suggesting Dixon's (2011) Foucauldian borrowing of surveillance constantly being exercised in the classroom to supervise behaviour rather than facilitate learning.

Little direct guidance or remedial instruction took place suggesting that the line of communication in the TLT triangle was primarily between the learner and the worksheet. Work that was not completed during class became homework for the next day, leaving those who did not finish (for whatever reason) to their own muddled devices. We did not witness how the worksheets were marked or how formative feedback was provided.

Our observational data did not reveal a worksheet used - as it could be - to scaffold or introduce new content, or vocabulary that would be familiar to the learners or needed reinforcing. Rather, several worksheets anticipated learners being able to respond in English at levels expected of a mother tongue speaker of a similar age.

In some classes, the numeracy worksheets were applied appropriately as learners moved from workstation to workstation where they measured or estimated, traced, weighed, recorded or counted, yet responses were all paperbased as learners marked off, underlined, linked or at best, wrote a sentence. No evidence of learning was provided orally or visually, for example, oral pair work, pasting or drawing. This reinforced the sense that the lead author has often noted the need for parents, line managers and subject advisors to be convinced of a teacher's input by a definite paper trail. No indication of how much time learners ought to spend on completing the worksheet was evident. Learners may have experienced a sense of achievement should they have managed to complete the work within the allocated time. This may also have helped them learn to focus and manage their time - an important life skill.

Worksheets seemed to be used primarily for classroom management rather than pedagogical purposes. Indeed, on most observed occasions, they were used for 'busy work', to keep one group of learners quiet whilst others finished an assigned task, or to fill time until the end of the school day.
Learning objectives provide the instructional target for both the teacher and learners, yet our observations did not reveal any episodes in which the learning objective was stated clearly, nor was the objective self-evident from the content and format of most worksheets. No worksheet was used as a scaffolding mechanism or as a guide during content exposition.

Most worksheets were handed out at the end of a lesson, presumably intended as revision of the lesson's content, but little reference was made to consolidate the connection. Some worksheets were used as a means of keeping learners busy whilst waiting for the next time slot. One teacher actually even stopped learners in the middle of the task to start new work with the comment that 'It does not matter if you didn't finish. It's just for fun!' There was negligible alignment between what had been taught during the lesson and the content of worksheets distributed.

The worksheets as our focused data source were indicative of varying degrees of instructional dissonance in the teachinglearning process and could, in most cases, easily be improved once student teachers had been sensitised to their effective design and implementation.

\section{Limitations and implications of the study}

Limitations of this nested study include limited data collected solely at urban schools with acceptable resourcing. Similar findings may manifest at rural schools where language barriers may be even greater or at poorly resourced schools where computerised production and duplication devices are rare. Secondly, it was not possible to home in on the precise correlation between the use of teacher-made worksheets and learners' acquisition of literacy, there being too many other variables involved. Finally, a more nuanced analysis may be achieved if the existing criteria were refined and applied more rigorously to other worksheets.

\section{Significance and implications of study}

The careful design and use of worksheets have the potential to provide fertile ground for exploring complex language and literacy matters especially in classrooms where the learners come from many different language backgrounds. Therefore, student teachers ought to understand why visual material needs to be scrutinised for how it could enhance language development rather than impede it. Whilst we could not deduce that misconceptions or incorrect facts were learned, classroom observations confirmed that many opportunities to foster literacies and broaden the learners' schemata were missed, leaving little doubt that there is still much to be accomplished in teacher education in order to dovetail classroom teaching to the experience, worldview and the learners' capability with the instructional language (Prochner et al. 2015). Post-observation guided conversations alerted students to the prevalence and subtleties of instructional dissonance and provided them with valuable 
insights into how to craft and implement worksheets more effectively. Based on our mentoring experiences, we compiled a checklist (see Appendix 1) that we deemed a useful guideline for creating worksheets and also introduced this topic to the curriculum of a related module for foundation phase students.

We recommend visual ethnography as a methodology not only for researchers but for teachers too, because it illuminates the importance of close scrutiny of the visual texts created for learners. It also asks teachers what their understandings are of such texts, sensitising them to tap into the meaning for the viewers of what is done and why, reminding us that individual and national development is also cultural, social and environmental. In line with Geertz's (1988) notion that the function of culture is to impose meaning on the world and make it understandable, 'truth' is indeed elusive, however, at the risk of taking an extreme position on the nature and quality of texts used in schools and classrooms, we would prefer a relativistic, or culturally aware approach, to one that attempts to uniformly make one size fit all.

Teacher education programmes need to include such matters as: awareness of second language learning principles in young children; the influence of culture in the content of the curriculum and the importance of aligning teaching to the learners' home-based experience with what they are ready to do or understand. These and similar topics ought to be a major unit within, if not run through, the entire teacher education curriculum. By paying careful attention to the creation of a key learning support tool such as a worksheet, the learners' confusion could be alleviated and their learning enhanced. This study thus brings to light evidence that the quality and use of worksheets rarely support learning and serve to amuse rather than challenge learners, pointing to a lost opportunity in the greater effort to establish literacy, and improve the quality of the teaching-learning process. Our study also adds impetus to the current and overdue calls to decolonise curricula (Dei 2014; Kirova et al. 2016a; Nsamenang \& Tchombe 2011; ed. Kumalo 2021; Serpell 2007) by, amongst others, guiding student teachers to become culturally responsive and to seek out or create more Afro-centric materials.

\section{Conclusion}

The careful crafting of a key learning support tool such as a worksheet, poster or flashcard would certainly alleviate some learners' bafflement and enhance the learning opportunity allowing them to 'see' what the teacher had intended. In this small-scale extract from our larger study, we attempted to highlight the importance of integrating indigenous perspectives with the so-called 'modern', zeroing in on the need to integrate diverse worldviews in the majority world. The imperative to contextualise learning support material and decolonise learning tasks becomes an undeniable obligation faced by the teacher, particularly in multicultural and multilingual contexts. We thus believe that well-designed worksheets could serve a more focused purpose and the link to literacy and learning of the instructional language (English) could be made more directly with improved teacher education on language learning issues and on how to design and implement visual learning support material more effectively.

\section{Acknowledgements Competing interests}

The authors declare that they have no financial or personal relationships that may have inappropriately influenced them in writing this article.

\section{Authors' contributions}

Both the authors contributed equally to this work.

\section{Ethical considerations}

This article followed all ethical standards for research without direct contact with human or animal subjects.

\section{Funding information}

This work is based on the research supported in part by the National Research Foundation of South Africa (Grant number: 119148).

\section{Data availability}

Data sharing is not applicable to this article as no new data were created or analysed in this study.

\section{Disclaimer}

The views and opinions expressed in this article are those of the authors and do not necessarily reflect the official policy or position of any agency of the authors.

\section{References}

Alonso-Sanz, A. \& Rueda, P., 2021, 'Who designs the classroom's images? Study of visual culture diversity at three Valencian schools', South African Journal of Education 41(1), 1-13. https://doi.org/10.15700/saje.v41n1a1824

Amila, A., Abdurrahman, W., Suyatna, A., Distrik, I.W. \& Herlina, K., 2018, 'Practicality and effectiveness of Student worksheets based on ethno science to improve conceptual understanding in rigid body', International Journal of Advanced Engineering, Management and Science 4(5), 400-407. https://doi.org/10.22161/ ijaems.4.5.11

Choo, S.S.Y., Rotgans, J.I., Yew, E.H.J. \& Schmidt, H.G., 2011, 'Effect of worksheet scaffolds on student learning in problem-based learning', Advances in Health Sciences Education 16, 517-528. https://doi.org/10.22161/ijaems.4.5.11

Çelikler, D., 2010, 'The effects of worksheets developed for the subject of chemical compounds on student achievement and permanent learning', The International Journal of Research in Teacher Education 1(1), 42-51.

Cleghorn, A. \& Prochner, L., 2010, Shades of globalization in three early childhood settings: Views from India, South Africa and Canada, Sense Publishers, Rotterdam.

Dei, J.S., 2014, 'Indigenizing the school curriculum', in J.S. Dei (ed.), African indigenous knowledge and the disciplines, pp. 165-180, Sense-Brill, Rotterdam.

Dixon, K., 2011, Literacy, power, and the schooled body-Learning in time and space, Taylor and Francis, Routledge, New York, NY.

Evans, R. \& Cleghorn, A., 2012, Complex classroom encounters: A South African perspective, Sense Publishers, Rotterdam.

Fauziah, A.M. \& Nurita, T., 2019, 'Activities of students in using worksheets based on contextual teaching and learning', Journal of Physics 1417, 012088. https://doi. org/10.1088/1742-6596/1417/1/012088 
Friends of the Earth, 2008, Considerations when designing worksheets, viewed 15 September 2015, from www.foe.co.uk/campaignhubs/index.php?action=media;s a=media;in=144; dl.

Frost, S., n.d., How to design effective paper worksheets, viewed 03 April 2012, from http://www.ehow.com/how_5755605_design-effective-paper-worksheets.html.

Gay, G., 2001, 'Preparing for culturally responsive teaching', Journal of Teacher Education 53(2), 106-116. https://doi.org/10.1177/0022487102053002003

Geertz, C., 1988, Works and lives, Stanford University Press, New York, NY.

Graham, B., 1998, Designing effective worksheets: Environmental education in botanic gardens training course, Kirstenbosch Botanic Garden, South Africa, viewed 03 April 2012, from http://www.bgci.org/education/designingeffectiveworksheets.

Hall, M. \& Russac, P., 2012, A year without worksheets, viewed 15 January 2016, from http://theasideblog.blogspot.co.za/2012/01/year-without-worksheets.html.

Hoyos Vivas, L.-M., 2021, 'Honouring cultural difference in early childhood education and care: Participatory research with a Colombian Embera Chami indigenous community', Doctoral dissertation, Concordia University, Montreal.

Kennedy, J., 2016, Ultimate guide to creating worksheets checklist, viewed 12 October 2016, from http://teachgoodstuff.com/about/.

Kirova, A., Massing, C., Prochner, L. \& Cleghorn, A., 2016a, 'Educating early childhood educators in Canada: A bridging program for immigrant and refugee childcare practitioners', Journal of Contemporary Educational Studies 2, 64-82. https://doi. org/10.1515/jped-2016-0004

Kirova, A., Massing, C., Prochner, L. \& Cleghorn, A., 2016b, 'Shaping the "habits of mind" of diverse learners in early childhood teacher education programs through PowerPoint: An illustrative case. Special issue: Resisting normal science in education', Journal of Pedagogy 7(1), 59-78.

Kumalo, S.H. (ed.), 2021, Decolonisation as democratisation: Global insights into the South African experience, HSRC Press, Pretoria.

Lee, C., 2014, 'Worksheet usage, reading achievement, classes' lack of readiness, and Science achievement: A cross country comparison', International Journal of Education in Mathematics, Science and Technology 2(2), 96-106. https://doi. org/10.18404/ijemst.38331

Marfo, K. \& Pence, A. (eds.), 2008, Strengthening Africa's contribution to child development research, SRCD, Victoria, BC.

Matengu, M., 2021, 'Towards just pre-primary education in rural Namibia', Doctoral dissertation, University of Oulo.

Matengu, M. \& Cleghorn, A., 2020, 'Whose African education is it?' in J.M. Abidogun \& T. Falola (eds.), The Palgrave handbook of African education and indigenous knowledge, pp. 671-682, Palgrave-MacMillan, New York, NY.

McEneaney, E.H., 2004, 'The global and the local in the construction of school science: The case of Canada', in A. Peacock \& A. Cleghorn (eds.), Missing the meaning: The development and use of print and non-print text materials in diverse schoo settings, pp. 13-32, Palgrave, New York, NY.

Mwaura, P. \& Marfo, K., 2011, 'Bridging culture, research and practice in early childhood development', Child Development Perspectives 5(2), 134-139. https:// doi.org/10.1111/j.1750-8606.2011.00168.x

Nsamenang, B. \& Tchombe, T. (eds.), 2011, Handbook of African theories and practices, Human Development Resource Centre, Bamenda.
Peacock, A. \& Cleghorn, A. (eds.), 2004, Missing the meaning: The development and use of print and non-print text materials in diverse school settings, Palgrave, New York, NY.

Peacock, A., Cleghorn, A. \& Mikkila-Erdmann, M., 2004, 'How can text and other learning materials be better matched to the preconceptions, expectations and inclinations of learners and teachers? Introduction to Section Three', in A. Peacock $\&$ A. Cleghorn (eds.), Missing the meaning: The development and use of print and $\&$ A. Cleghorn (eds.), Missing the meaning: The development and use of print and
non-print text materials in diverse school settings, pp. 181-196, Palgrave, non-print text
New York, NY.

Pink, S., 2013, Doing visual ethnography: Images, media and representation in research, Sage, London.

Prochner, L., Cleghorn, A. \& Green, N., 2008,' Space considerations: Materials in the learning environment in three majority-world preschool settings', International Journal of Early Years Education 16(3), 189-201. https://doi.org/10.1080/ Journal of Early Years
09669760802343857

Prochner, L., Cleghorn, A., Kirova, A. \& Massing, C., 2014, 'Culture and practice in early childhood teacher education', in N. Popov, C. Wolhuter, K. Ermenc, G. Hilton, J. Ogunleye \& O. Chigisheva (eds.), Education's role in preparing globally competent citizens. BCES Conference Books, vol. 12, pp. 39-46, Bulgarian competent citizens. BCES Conference
Comparative Education Society, Sofia.

Prochner, L., Cleghorn, A., Kirova, A. \& Massing, C., 2015, 'Early childhood teacher education in Namibia and Canada', in N. Popov \& A.W. Wiseman (eds.), Interdisciplinary perspectives on education and society, vol 26: Comparative Interdisciplinary perspectives on educt
sciences, pp. 87-98, Emerald, Bingley.

Röken, F., 2015, Worksheets for the classroom: Structure, form and content, Goethe Institut, viewed 15 January 2016, from https://www.goethe.de/en/spr/ mag/20577548.html.

Sasmaz-Ören, F. \& Ormanci, U., 2012, 'An application about pre-service teachers' development and use of worksheets and an evaluation of their opinions about the application', Educational Sciences: Theory and Practice 12(1), 263-270.

Serpell, R., 2007, 'Bridging between orthodox western higher educational practices and an African sociocultural context', Comparative Education 43(1), 23-51. https://doi.org/10.1080/03050060601162396

Simbolon, N., Simanjuntak, E.B., Simarmata, J. \& Khairina, M., 2018, 'The development of students' activity sheets with a scientific approach in elementary school', Journal of Physics Conference Series 1114, 012040. https://doi.org/10.1088/1742 $6596 / 1114 / 1 / 012040$

Töman, U., Akdeniz, A.R., Odabasi Çimer, S. \& Gürbüz, F., 2013, 'Extended worksheet developed according to $5 \mathrm{E}$ model based on constructivist learning approach', International Journal on New Trends in Education and Their Implications 4(4), 173-183.

University of Texas, 2010, Well-crafted worksheet, viewed 03 October 2020, from https://uteach.utexas.edu/sites/default/files/2010-10-08\%20WellCrafted\%20Worksheet.pdf.

Van Den Scott, L.K., 2018, 'Visual methods in ethnography', Journal of Contemporary Ethnography 47(6), 719-728. https://doi.org/10.1177/0891241618806972

Van der Walt, C. \& Evans, R., 2019, Learn 2 teach: English language teaching in a multilingual context, 4th edn., J.L. van Schaik Publishers, Pretoria.

Worksheet Library, 2007, viewed 15 September 2015, from http://www. worksheetlibrary.com/teachingtips/5stepstoworksheets.html. 


\section{Appendix 1}

TABLE 1-A1: Designing and implementing worksheets.

Checklist

1 Pedagogical intent

What is the purpose (learning outcome) of the worksheet?

Have the tasks been sequenced appropriately in order to achieve the learning outcome?

Is there sufficient scaffolding?

Do tasks move from the simple to the more complex?

Do learners know how long to spend completing the tasks?

Have examples been provided?

What action ought to follow on completion of the worksheet?

\section{Visual appeal}

Are illustrations clear in terms of proportion and detail?

Has a consistent style been used?

Are illustrations relevant? Do they add to the learning?

Is the look-and-feel appropriate for the age group?

Is there sufficient white space? Page too busy?

Is there visual signposting to guide learners?

\section{Language}

Are the instructions simple and clear?

Has the grammar been checked?

Is the language used age appropriate?

\section{Cultural sensitivity}

Are the learners able to identify with the visual representations?

Can learners respond adequately to images and vocabulary used?

Do any images reinforce stereotypes or create offense?

Has the content been localised?

\section{Technical matters}

Is there sufficient space to write answers as required?

Has referencing detail been provided (Heading/Topic, learner's name, grade, date, teacher's name, designer of work sheet, parental signature)?

Has the source of the content/origin of the worksheet been indicated?

Is the choice of font and its size age-appropriate?

Will duplicated copies of the worksheet be legible?

Is the layout too busy?

Have the pages been numbered?

Have the tasks been numbered?

\section{Implementation}

How will learners complete the worksheet (individually, in pairs or as a group)?

At what stage of the lesson will the worksheet be used (start/during/end/ homework)?

Will the learners be static or moving between stations?

Could a coloured/enlarged version be projected/pasted up for ease of reference?

Do learners know what to do with the completed/marked worksheet? 